\title{
ORIGINAL ARTICLE Prognostic significance of Versican expression in gastric adenocarcinoma
}

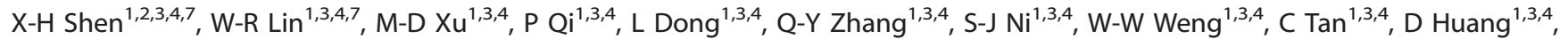 \\ Y-Q Ma ${ }^{5}$, W Zhang ${ }^{5}$, W-Q Sheng ${ }^{1,3,4}, Y-Q$ Wang $^{6,8}$ and $X \mathrm{Du}^{1,3,4,8}$
}

Gastric cancer (GC) is the leading malignancy in the digestive system. Versican is a ubiquitous component of the extracellular matrix and has a role in tumor progression. We aim to examine the expression of Versican in GC and the relationship between Versican levels and patient survival. We detected the mRNA expression of Versican in tumorous pairs and adjacent normal tissues (ANTs) of 78 GC patients by quantitative real-time polymerase chain reaction. The protein expression of Versican in 101 cases of matched GC and ANT, as well as in 27 intraepithelial neoplastic (IN) samples, was evaluated by immunohistochemistry. We analyzed the correlation between Versican levels and clinical outcomes. Finally, we performed CCK-8 cell counting assay and transwell assay in GC cell lines. Versican mRNA expression was significantly greater in tumor tissues $(P<0.001)$ than in ANT. Versican was majorly expressed in the stroma surrounding tumor epithelium and minorly some areas of tumor epithelium. The Versican expression level was higher in GC than in ANT $(P=0.004)$, but no significant difference was observed between ANT and IN $(P=0.517)$. The Versican mRNA and protein levels were consistent in GC. High Versican mRNA and protein expression correlated with greater tumor invasion depth $(P=0.030, P=0.027)$. Univariate and multivariate analysis revealed that patients with high Versican mRNA expression exhibited poor disease-specific survival $(P<0.001)$. In vitro experiments showed that Versican overexpression promoted cell proliferation and invasion. Our data indicate that Versican may be a novel prognostic indicator in GC and may be a potential target for clinical diagnosis.

Oncogenesis (2015) 4, e178; doi:10.1038/oncsis.2015.36; published online 30 November 2015

\section{INTRODUCTION}

Gastric cancer (GC) remains one of the most common malignancies and most frequent cause of cancer death. ${ }^{1,2}$ The majority of GC is gastric adenocarcinoma, which has a relatively high 5-year survival rate despite of the early-stage diagnosis.' Clinical prognostic factors such as histological type and stage supply limited predictive information for the subsequent treatment of gastric adenocarcinoma, and new biological markers are in demand to achieve the most effective diagnostic method.

The extracellular matrix (ECM), composed of proteoglycans (PGs), glycoproteins and collagens, is a highly organized structure with many physiological and pathological roles. ${ }^{3}$ Modifying the ECM composition through a large array of molecules, as well cell-cell and cell-matrix interactions, may be crucial for tumor initiation and progression. ${ }^{4}$ PGs, a group of heavily glycosylated proteins, are present throughout the mammalian body and are involved in a wide variety of biological phenomena, including structural maintenance, tissue remodeling, molecular presentation, cellular adhesion and signal transmission. Using intracellular signaling pathways, PG and growth factor signals are transmitted and alter the cellular response, ${ }^{5}$ thus, PGs are directly implicated in a large variety of human diseases. Several studies indicated that significant PG content changes occur in the tumor stroma of epithelial neoplasms, thereby supporting tumor growth and invasion. Versican, a member of the aggregating chondroitin sulfate PGs family, ${ }^{6}$ is accumulated predominantly in the tumor stroma, ${ }^{7}$ providing hygroscopic properties to create a loose and hydrated matrix that is necessary to support key events in development and disease. Through direct or indirect interactions with cells and molecules, Versican has significant roles in modulating cell proliferation, differentiation, adhesion and migration, all of which are features of cancer invasion and metastasis. ${ }^{8}$ Thus, Versican may serve a wide range of functions in the invasion and metastasis of tumor cells.

Previous studies have shown that Versican can be detected in many malignancies including melanoma, non-small cell lung cancers, breast tumors, ${ }^{9-12}$ pharyngeal, ${ }^{13}$ ovarian cancer ${ }^{7,14}$ and cervical cancer. ${ }^{15}$ Increased accumulation of structurally modified Versican is reportedly related to the progression of laryngeal cancer. ${ }^{16}$ However, the significance of Versican has been less extensively studied in gastric adenocarcinoma. The aim of our study was to investigate Versican expression in gastric adenocarcinoma and to determine its relationship with clinicopathologic factors, with a special emphasis on its prognostic significance.

\section{RESULTS}

Versican expression in tissues

The first goal of our study was to investigate whether Versican is detectable and altered in gastric adenocarcinoma tissues

\footnotetext{
${ }^{1}$ Department of Pathology, Fudan University Shanghai Cancer Center, Shanghai, China; ${ }^{2}$ Clinical and Pathological Diagnosis Center, Ningbo, China; ${ }^{3}$ Institute of Pathology, Fudan University, Shanghai, China; ${ }^{4}$ Institute of Biomedical Sciences, Fudan University, Shanghai, China; ${ }^{5}$ Department of Pathology, First Hospital Affiliated to Xinjiang Medical University, Wulumuqi, China and ${ }^{6}$ Department of Pathology, Obstetrics and Gynecology Hospital of Fudan University, Shanghai, China. Correspondence: Dr X Du, Department of Pathology, Fudan University Shanghai Cancer Center, Dong'an Road 270\#, Xuhui District, Shanghai 200032, China.

E-mail: dx2008cn@163.com

${ }^{7}$ These authors contributed equally to this work.

${ }^{8}$ These authors are co-corresponding authors of this article.

Received 23 June 2015; revised 22 September 2015; accepted 23 September 2015
} 
compared with adjacent normal ones. So we performed quantitative real-time (RT) polymerase chain reaction with RNAs isolated from gastric adenocarcinoma tissues to detect the expression levels of Versican. It turned out that Versican expression was significantly greater in tumor tissues compared with adjacent normal tissues (ANTs; $P<0.001$; Figure 1), suggesting that Versican was highly expressed in malignant gastric adenocarcinoma.

Versican expression in GC tissues, IN and ANTs

Next, we performed immunohistochemistry to examine the protein expression of Versican in 101 GC tissue samples, 100 ANT samples (one sample missing) and 27 intraepithelial neoplastic (IN) samples. First, we observed that the staining of Versican was in nucleus or both nucleus and cytoplasm. The staining areas majorly covered the stromal cells characteristically surrounding the epithelial lesions, and also covered some part of the epithelium of cancer areas (Figures 2a-d). The staining of Versican was significantly more intense in gastric adenocarcinoma cases than that in either IN or ANT tissues (Figures 2a-d). When scored using the Ruiter et al. scoring system, ${ }^{13,17}$ more cases with high Versican expression were observed in gastric

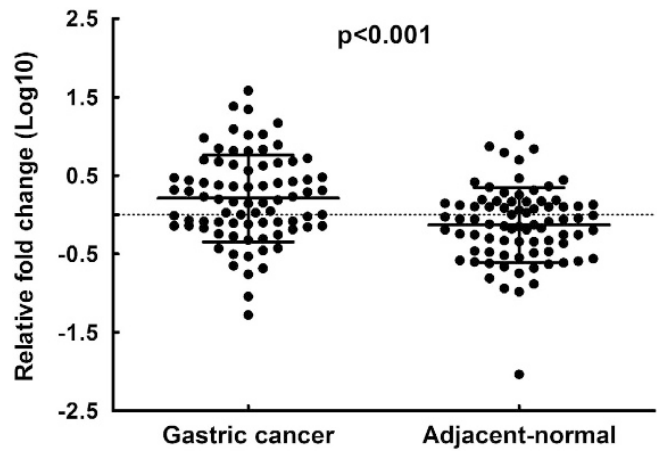

Figure 1. Versican expression as assessed by quantitative RT polymerase chain reaction (qRT-PCR) in cancerous tissue (GC) and adjacent normal mucosa (ANT). Versican expression was significantly higher in cancerous tissues compared with ANTs. Data represent means \pm s.d. $(P<0.001)$. Beta-actin was used as an endogenous control to normalize the data. adenocarcinoma (78 out of 101, 77.23\%; Figure 2e). Compared with IN (17 out of 27,62.96\%; Figure 2f) and ANT (33 out of 100, $33.00 \%$; Figure $2 \mathrm{~g}$ ), the proportion of high Versican expression was significantly larger in gastric adenocarcinoma than that in either IN $(P=0.004)$ or ANT $(P=0.000$; Figure $2 \mathrm{~h})$.

Furthermore, we chose 50 cases with both results of RT-quantitative polymerase chain reaction (qPCR) in tumor tissues and immunochemistry in paraffin sections to examine the correlation between mRNA level and protein expression of Versican. As shown in figure, the mRNA levels of Versican in these 50 cases were highly correlated with protein expression levels in immunochemistry (Figure 3). Taken together, these data suggested that Versican was highly expressed in gastric adenocarcinoma both on mRNA and protein levels.

\section{Versican expression and clinicopathological factors of GC}

To assess the correlation between the Versican expression and clinicopathological data, the Versican expression in tumor tissues were categorized as low or high by the median value. ${ }^{18}$ At both the mRNA and protein levels, elevated Versican expression was correlated with greater tumor invasion than lower expression $(P=0.030$ and $P=0.027$, respectively). There was no significant correlation between Versican expression and other clinicopathologic features, such as age, gender, tumor size, tumor location, histologic grade, lymphatic metastasis, peritoneal metastasis, vascular invasion, nervous invasion or tumor stage $(P>0.05$ Table 1).

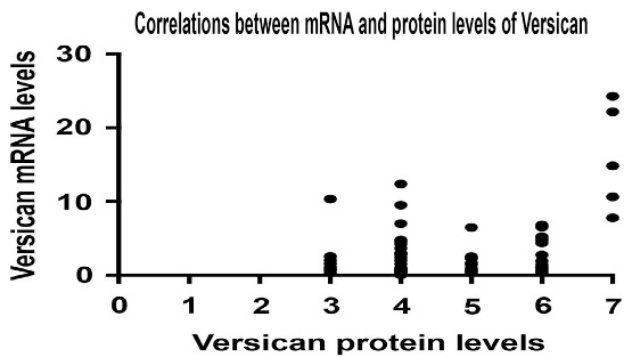

Figure 3. The correlation between mRNA and protein levels of Versican in gastric adenocarcinoma. A Pearson correlation analysis was done between the mRNA levels of and protein levels of Versican in 78 patients with gastric adenocarcinoma. $(R=0.344, P<0.01)$.
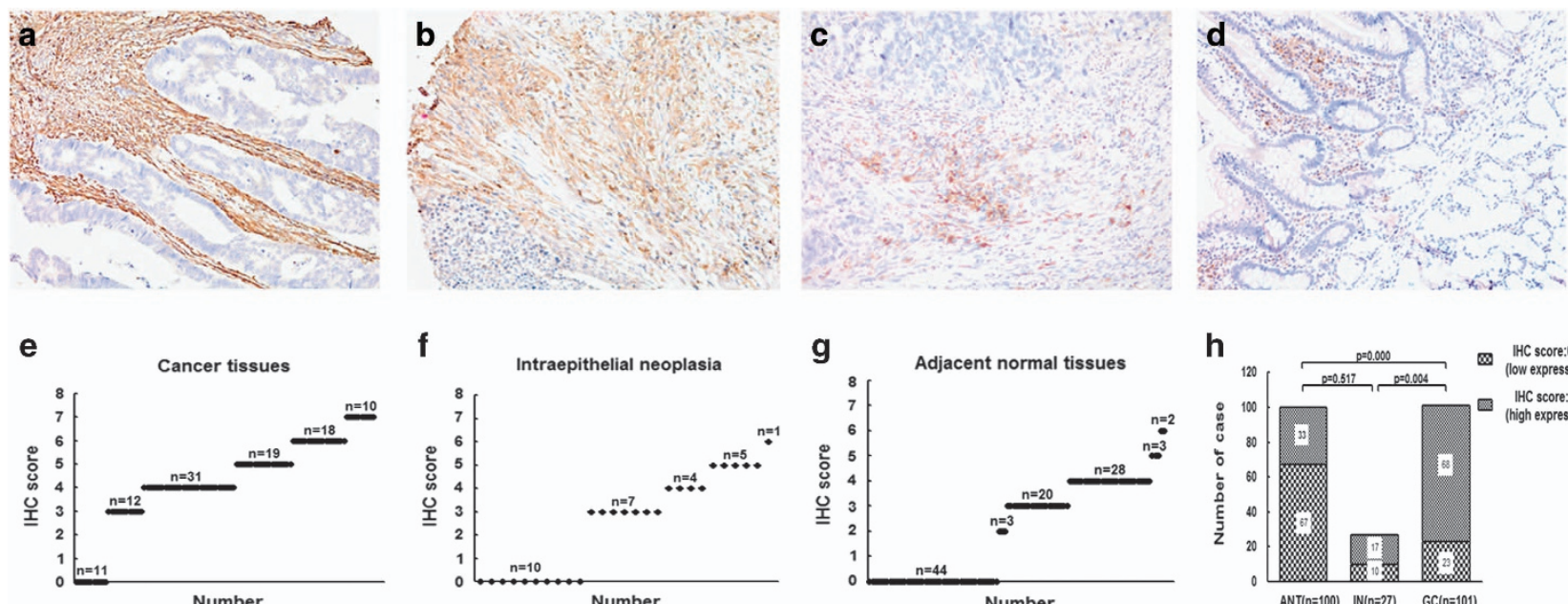

f

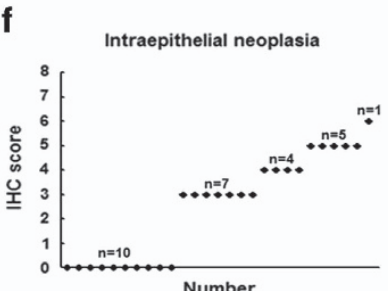

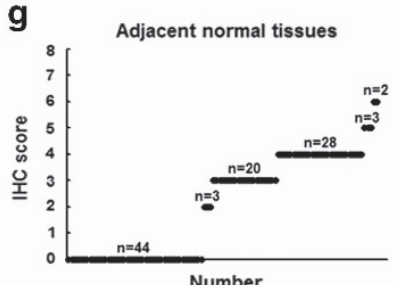

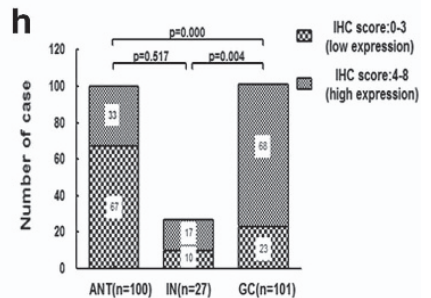

Figure 2. Versican expression as assessed by immunohistochemistry in cancerous tissue, IN and adjacent normal mucosa. Representative immunostaining results of Versican in (a) GC (moderately differentiated), intense stromal Versican staining; (b) GC (poorly differentiated), moderate stromal Versican staining; (c) GC (poorly differentiated), mild stromal Versican staining; (d) IN, mild stromal Versican staining (x200 magnification). IHC score of stromal Versican expression in (e) GC, (f) IN and (g) ANT. (h) Scoring differences between GC and ANT, GC and IN, and ANT and IN $(P=0.000, P=0.004$ and $P=0.517$, respectively). 
Table 1. Relationship between Versican expression and clinicopathologic parameters of gastric cancer patients

\begin{tabular}{|c|c|c|c|c|c|c|}
\hline \multirow[t]{2}{*}{ Variables } & \multicolumn{3}{|c|}{ mRNA expression } & \multicolumn{3}{|c|}{ Protein expression } \\
\hline & $\begin{array}{c}\text { Low } \\
(\mathrm{n}=57)\end{array}$ & $\begin{array}{c}\text { High } \\
(\mathrm{n}=21)\end{array}$ & $\mathrm{P}$-value $\mathrm{a}^{\mathrm{a}}$ & $\begin{array}{l}\text { Low } \\
(\mathrm{n}=31)\end{array}$ & $\begin{array}{c}\text { High } \\
(\mathrm{n}=70)\end{array}$ & P-value \\
\hline \multicolumn{7}{|l|}{ Age (years) } \\
\hline$<60$ & 25 & 11 & & 17 & 34 & \\
\hline$\geqslant 60$ & 32 & 10 & 0.339 & 14 & 36 & 0.358 \\
\hline \multicolumn{7}{|l|}{ Gender } \\
\hline Male & 44 & 18 & & 25 & 55 & \\
\hline Female & 13 & 3 & 0.314 & 6 & 15 & 0.520 \\
\hline \multicolumn{7}{|c|}{ Tumor mass size } \\
\hline$<5 \mathrm{~cm}$ & 37 & 15 & & 17 & 50 & \\
\hline$\geqslant 5 \mathrm{~cm}$ & 20 & 6 & 0.399 & 14 & 20 & 0.082 \\
\hline \multicolumn{7}{|l|}{ Location } \\
\hline $\begin{array}{l}\text { Upper } \\
\text { stomach }\end{array}$ & 12 & 5 & & 7 & 12 & \\
\hline $\begin{array}{l}\text { Middle } \\
\text { stomach }\end{array}$ & 16 & 5 & & 9 & 22 & \\
\hline $\begin{array}{l}\text { Lower } \\
\text { stomach }\end{array}$ & 22 & 9 & & 11 & 25 & \\
\hline $\begin{array}{l}\text { Entire } \\
\text { stomach }\end{array}$ & 7 & 2 & 0.955 & 4 & 11 & 0.921 \\
\hline \multicolumn{7}{|l|}{ Histologic grade } \\
\hline $\begin{array}{l}\text { Well and } \\
\text { moderately }\end{array}$ & 5 & 15 & & 21 & 53 & \\
\hline $\begin{array}{l}\text { Poorly and } \\
\text { others }\end{array}$ & 16 & 42 & 0.536 & 10 & 17 & 0.274 \\
\hline \multicolumn{7}{|l|}{ Depth of tumor } \\
\hline $\mathrm{T} 1$ and $\mathrm{T} 2$ & 15 & 1 & & 2 & 17 & \\
\hline $\mathrm{T} 3$ and T4 & 42 & 20 & 0.030 & 29 & 53 & 0.027 \\
\hline \multicolumn{7}{|c|}{ Vascular invasion } \\
\hline Absent & 25 & 9 & & 7 & 14 & \\
\hline Present & 32 & 12 & 0.573 & 24 & 56 & 0.480 \\
\hline \multicolumn{7}{|c|}{ Nervous invasion } \\
\hline Absent & 27 & 6 & & 22 & 55 & \\
\hline Present & 30 & 15 & 0.108 & 9 & 15 & 0.279 \\
\hline \multicolumn{7}{|c|}{ Lymphatic metastasis } \\
\hline Absent & 19 & 6 & & 9 & 25 & \\
\hline Present & 38 & 15 & 0.456 & 22 & 45 & 0.338 \\
\hline \multicolumn{7}{|c|}{ Peritoneal metastasis } \\
\hline Absent & 47 & 16 & & 13 & 29 & \\
\hline Present & 10 & 5 & 0.372 & 18 & 41 & 0.566 \\
\hline \multicolumn{7}{|l|}{$T N M$ stage $^{\mathrm{b}}$} \\
\hline I and II & 23 & 6 & & 13 & 31 & \\
\hline III and IV & 34 & 15 & 0.247 & 18 & 39 & 0.501 \\
\hline
\end{tabular}

Correlation between Versican expression and GC patient prognosis

Disease-specific survival (DSS) curves were plotted according to Versican mRNA expression levels using the Kaplan-Meier method. During follow-up, 20 patients died of gastric adenocarcinoma. As presented in Figure 4, the patients with high Versican expression exhibited a significantly poorer prognosis than those with low Versican expression $(P<0.001)$. Univariate analysis of DSS revealed that the relative level of Versican expression $(P<0.001$;

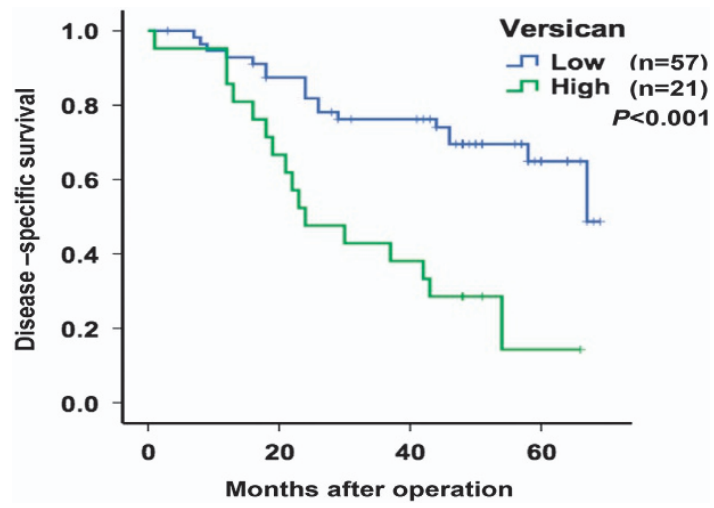

Figure 4. Kaplan-Meier survival curves of patients with different expression levels of Versican in GC. Patients with high Versican expression levels $(n=57)$ exhibited significantly poorer prognoses than those with low Versican expression levels $(n=21, P=0.000)$. $P$-values were calculated using the log-rank test.

Figure 4), tumor depth $(P=0.020)$, nervous invasion $(P=0.024)$, lymphatic metastasis $(P=0.004)$, peritoneal metastasis $(P=0.027)$ and tumor stage $(P<0.001)$ were prognostic indicators (Table 2$)$. The other clinicopathological features, such as age, gender, tumor size, tumor location, histologic grade and vascular invasion, were not statistically significant prognosis factors $(P>0.05$; Table 2). Multivariate analysis revealed that in addition to the tumor stage $(P=0.001)$, Versican expression was an independent prognostic indicator for DSS in GC patients ( $P=0.002$; Table 2$)$.

Overexpression of Versican promotes tumor cell proliferation and invasion in gastric carcinoma

Finally, we turned to verify the biological functions of Versican in vitro. We detected the mRNA level of Versican in normal GES1 and five gastric carcinoma cell lines by RT-qPCR first (Figure 5a), and chose MKN45 and AGS as the candidate cell lines for interference (Figure 5b). Then, we used the Cell Counting Kit- 8 (CCK-8) assay to examine the potential influence of Versican on cell proliferation in GC cell lines. As shown in figure, overexpression of Versican stimulated cell proliferation in MKN45 and AGS cells (Figure 5c). Next, we performed the Transwell assay to investigate the effect of Versican on cell invasiveness. Similarly, overexpression of Versican enhanced cell invasion in MKN45 and AGS cells (Figure $5 \mathrm{~d}$ ). These data together suggested that Versican promoted tumor cell proliferation and invasion in gastric carcinoma.

\section{DISCUSSION}

As far as it is concerned, our study is the first to report data for the prospective power of Versican expression in clinical cohorts. We found that Versican expression is associated with the clinicopathological features and prognosis of GC. We speculate that dysregulated Versican expression may contribute to GC development and/or progression, as well as to the prognosis of GC patients. Thus, Versican may be applied as a biomarker for malignancy and monitoring prognosis in gastric adenocarcinoma clinically.

Versican has been observed in many malignancies, including melanoma, epithelial ovarian cancer, breast cancer and non-small cell lung cancer, ${ }^{7,9-11,15}$ implying its importance in tumor maintenance. Stylianou et al. ${ }^{16}$ reported a 140 -fold increase in Versican expression in laryngeal cancer tissue relative to normal controls. In serous ovarian cancer, Versican was reportedly expressed at significantly greater levels in tumor samples versus normal ovarian tissues. ${ }^{14}$ In our study, we first investigated altered 
Table 2. Univariate and multivariate analysis of clinicopathological factors for disease special survival in gastric cancer

\begin{tabular}{|c|c|c|c|c|}
\hline \multirow[t]{2}{*}{ Variable } & \multicolumn{2}{|c|}{ Univariate analysis } & \multicolumn{2}{|c|}{ Multivariate analysis } \\
\hline & $H R(95 \% \mathrm{Cl})$ & $\mathrm{P}$-value $\mathrm{a}^{\mathrm{a}}$ & $H R(95 \% \mathrm{Cl})$ & $\mathrm{P}$-value $\mathrm{a}^{\mathrm{a}}$ \\
\hline Gender (male/female) & $0.991(0.432-2.269)$ & 0.982 & & \\
\hline Tumor size $(<5 / \geqslant 5)$ & $1.678(0.863-3.261)$ & 0.127 & & \\
\hline Tumor location (upper/middle/lower/diffuse) & $1.015(0.715-1.442)$ & 0.932 & & \\
\hline Nervous invasion (absent/present) & $2.605(1.223-5.548)$ & 0.013 & $1.198(0.498-2.887)$ & 0.687 \\
\hline Lymphatic metastasis (absent/present) & $3.924(1.521-10.124)$ & 0.005 & $1.036(0.133-8.0956)$ & 0.973 \\
\hline TNM stage $(I+I I / I I I+I V)$ & $5.567(2.149-14.418)$ & 0.000 & $7.711(2.322-25.609)$ & 0.001 \\
\hline Versican (low/high) & $3.739(1.933-7.232)$ & 0.000 & $3.089(1.533-6.226)$ & 0.002 \\
\hline
\end{tabular}

Versican expression in 78 pairs of GC and ANT samples by RT-qPCR and confirmed that Versican expression was significantly greater in 78 GC tumor tissues relative to the respective ANT samples. Together with our studies of gastric adenocarcinoma, these data support the view that Versican mRNA expression levels may be associated with cancer development.

In different cancers, Versican deposits have been demonstrated both in tumor stroma ${ }^{19,20}$ and in tumor cells. ${ }^{12}$ Analyses of mRNA have also demonstrated that tumor-associated Versican is synthesized both in the peritumoral stroma and in the tumor itself. ${ }^{21}$ Our study suggested that Versican expression was only detected in the tumor stroma surrounding epithelial lesions in gastric adenocarcinoma without any supplementary intracellular Versican accumulation, thereby suggesting that in GC, Versican is likely predominantly synthesized in the tumor stroma by stromal fibroblasts. The effects of stromal Versican expression on tumor progression may be dependent on the organ and tumor type examined.

Previous studies concerning Versican immunohistochemical staining have revealed that stromal Versican expression was significantly greater in the patients with advanced disease. ${ }^{7}$ Our data detected statistically significant differences in Versican expression levels between gastric adenocarcinoma and ANT, as well as between gastric adenocarcinoma and IN. The group with higher Versican mRNA and protein expression exhibited deeper tumor invasion than the lower Versican expression group. Moreover, we observed that patients with high Versican expression exhibited poor DSS, and multivariate analysis revealed that Versican expression was an independent prognostic indicator for DSS. Versican may be an applicable prognostic predictor and monitor for gastric adenocarcinoma in clinical practice. Future studies may testify its value in prognostic prediction in a larger sample of gastric adenocarcinoma or a sample containing multiple histological subtypes of gastric malignancies.

Neoplastic remodeling of the ECM by modulating stromal cell secretion of macromolecules, such as Versican, is a wellrecognized phenomenon and may be one mechanism by which tumor cells control their microenvironment to facilitate local invasion and metastasis. ${ }^{12,13,16,22,23}$ Considering the correlation of high Versican expression with tumor metastasis and recurrence found in our study, Versican may promote tumor progression by prompting tumor invasion. We further identified that Versican was critical for enhancement of cancer cell proliferation as well as tumor cell invasion in vitro. As a ubiquitous component of the ECM, Versican is expressed and secreted by fibroblasts present in the tumor stroma and is likely regulated by transforming growth factor beta ${ }^{17,24-26}$ and is also a target gene of Wnt signaling. ${ }^{27}$ The interplay of these factors may lead to different Versican expression levels in various tumor types. Indeed, Zhang et al. ${ }^{28}$ have suggested that Versican may exhibits biological effects in GC development by its two major functional isoforms $\mathrm{V} 0$ and $\mathrm{V} 1$, after triggered by an important cytokine interleukin-11, both isoforms participate in GC cells migration. The wide ranging functions of Versican have been attributed to its central glycosaminoglycan binding region, and to the $\mathrm{N}-(\mathrm{G} 1)$ and $\mathrm{C}-(\mathrm{G} 3)$ terminal globular domains, which collectively interact with a large number of ECM and cell surface structural components. ${ }^{8}$ Nevertheless, it is likely that target genes differ between specific tissues and cell types, and the specific target genes controlled by Versican in GC remain unknown. In future work, high-throughput techniques such as RNA sequencing and microarray analysis should be applied to obtain a global view of the changes of downstream molecules, thereby elucidating the regulation mechanisms of Versican.

\section{Conclusion}

Our results show that Versican expression is significantly increased in GC tissues. Greater Versican expression levels were detected in more invasive tumors. In addition, the upregulation of Versican expression was associated with poor GC prognosis. These findings suggested that Versican may be a novel prognostic indicator in GC and may be a specific and accessible biomarker as well as a potential new target for GC clinical diagnosis.

\section{MATERIALS AND METHODS}

Tissue samples and clinical data collection

This study collected all 78 tissues of patients with gastric adenocarcinoma stored in tissue bank of Shanghai Cancer Center from 2009 to 2014. All the patients analyzed in this study underwent resection of primary gastric adenocarcinoma at Fudan University Shanghai Cancer Center from 2009 to 2014. All the cases were histopathologically confirmed as gastric adenocarcinoma according to WHO classifications of Tumors of Digestive System 2010 version. None of the patients underwent pre-operative treatment. All the resected tissue samples were immediately frozen in liquid nitrogen and stored at $-80^{\circ} \mathrm{C}$ until RNA extraction in the tissue bank. The data collected from all subjects included age, gender, DSS and clinicopathological features (for example, tumor size, location, histologic stage, depth of invasion, status of venous invasion, nervous invasion, lymphatic metastasis and peritoneal metastasis). The clinical stage was evaluated using the TNM classification system. ${ }^{29}$ Patient follow-up was performed every 2-3 months during the first postoperative year and 3-6 months thereafter, until 30 July 2015. All patients completed the follow-up. The DSS was defined as the length of time between the surgery and death from the cancer. During the follow-up, 20 patients died of disease. This study was approved by the research ethics committee of Fudan University Shanghai Cancer Center, and the participants provided informed consent for the use of their tissues in this study. 
a

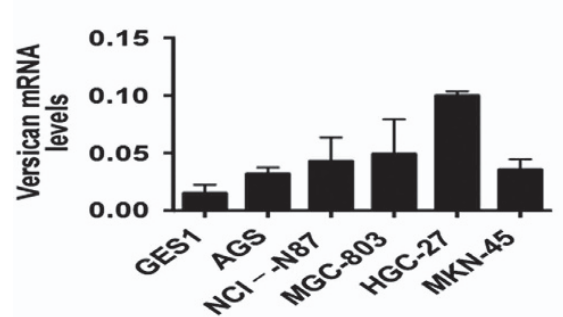

C

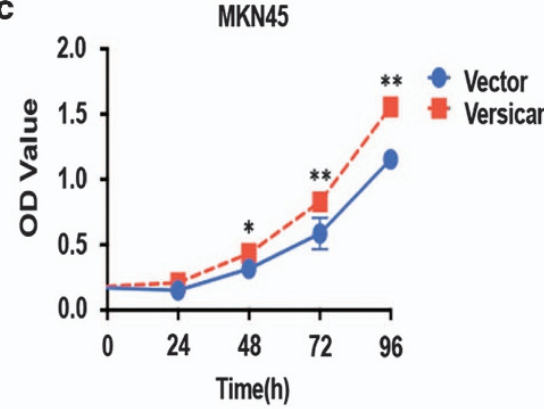

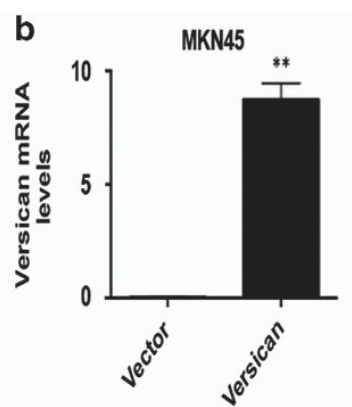
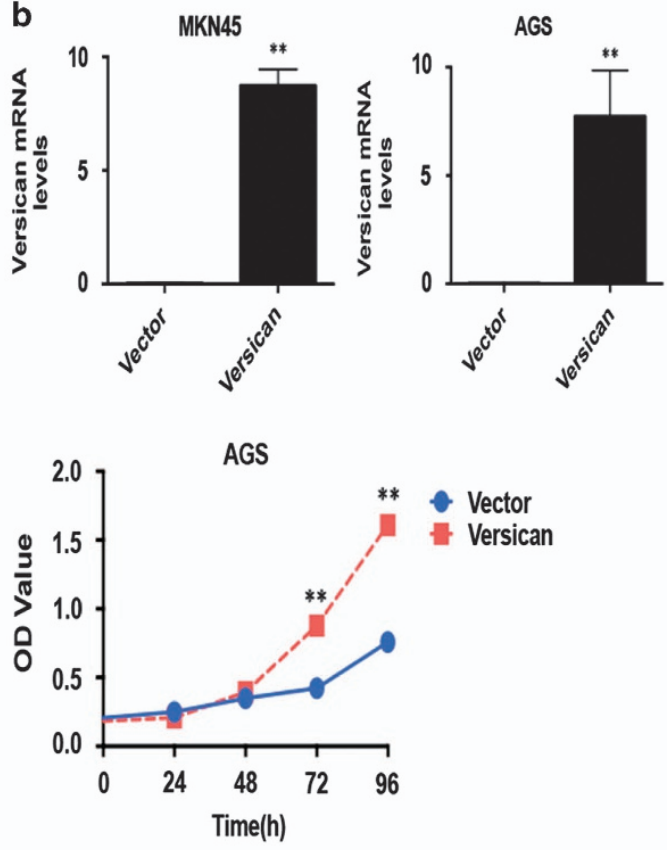

d
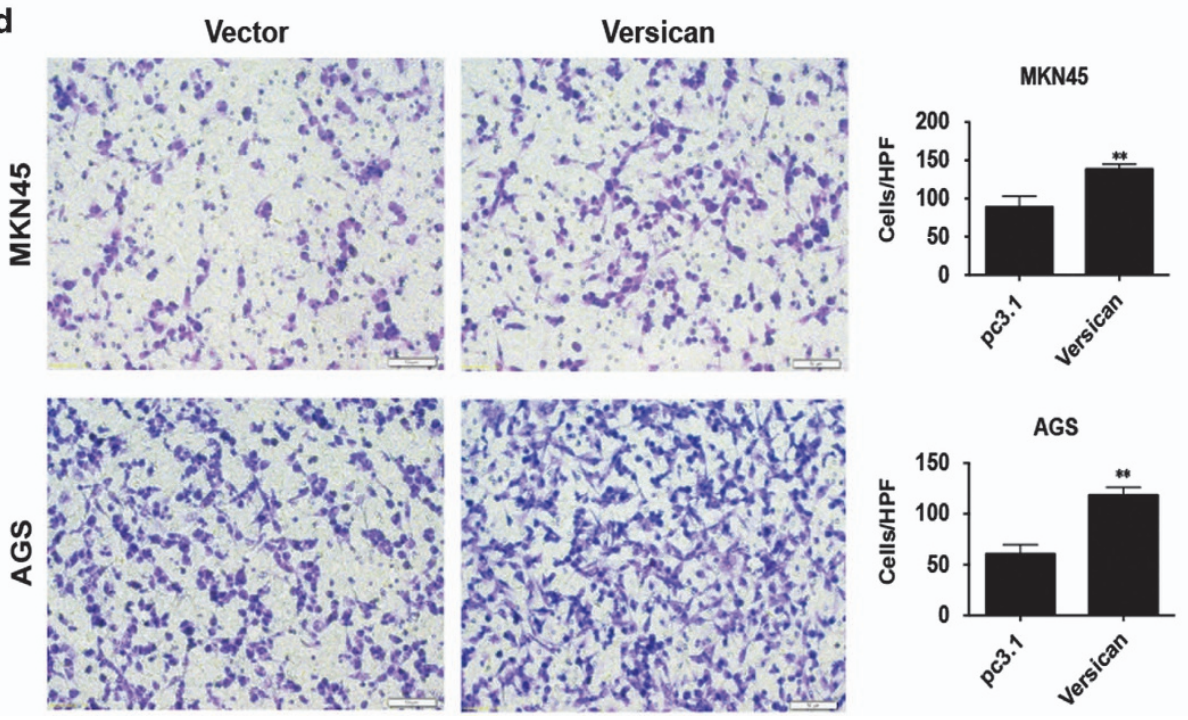

Figure 5. Overexpression of Versican promoted tumor cell proliferation and invasion in GC cell lines. (a) The mRNA levels of Versican were detected by RT-qPCR in GES1 and five GC cell lines. (b) The efficiencies of Versican in MKN45 and AGS cells were detected by RT-qPCR. (c) CCK-8 assay was performed to detect the influence of overexpression of Versican on tumor cell proliferation in MKN45 and AGS cells. ${ }^{*} P<0.05$; ${ }^{* *} P<0.01$. (d) Transwell assay was performed to detected the influence of overexpression of Versican on tumor cell invasion in MKN45 and AGS cells. ${ }^{* *} P<0.01$.

RNA preparation, reverse transcription and quantitative RT polymerase chain reaction

Total RNA was extracted from the tumorous and ANTs using Trizol (Invitrogen, Carlsbad, CA, USA) following the manufacturer's protocol. RT and qPCR kits were used to evaluate the Versican expression from tissue samples. The RT and $\mathrm{qPCR}$ reactions were performed as previously described. ${ }^{20}$ Relative gene expression was calculated using the comparative cycle threshold (CT) $\left(2^{-\Delta \Delta C T}\right)$ method, with beta-actin as the endogenous control to normalize the data. ${ }^{30}$ The following primers were used in this study: Versican, 5'-GATGTGTATTGTTATGTGGATCA-3' (forward) and $5^{\prime}$-CATCAAATCTGCTATCAGGG-3' (reverse); and beta-actin, 5'-TCCTCT CCCAAGTCCACACA-3' (forward) and 5'-GCACGAAGGCTCATCATTCA-3' (reverse).
Immunohistochemistry and evaluation of immunohistochemical staining

A total of 101 GC sample pairs and 27 IN samples were studied. Slides and paraffin blocks were selected from the archives of the Pathology Department of Fudan University Shanghai Cancer Center. Immunohistochemical analysis was performed using 4- $\mu$ m paraffin sections mounted on aminopropyl-triethoxysilane-coated slides. Sections were deparaffinized, rehydrated and treated with $0.3 \% \mathrm{H}_{2} \mathrm{O}_{2}$ in methanol for 20 min to block endogenous peroxidase activity. Antigen retrieval was performed $(0.01 \mathrm{M}$ citrate, $\mathrm{pH} 6.0$ ), and the sections were rinsed in phosphate-buffered saline. Subsequently, the sections were stained for Versican (overnight) using a 1:200 dilution of rabbit polyclonal anti-human Versican (ab111072, Abcam, Hong Kong, China) in phosphate-buffered saline containing $1 \%$ bovine 
serum albumin. Subsequently, the slides were incubated with PowervisionPoly-HRP-goat anti-mouse/rat/rabbit IgG (Gene Tech, Shanghai, China), and immune complexes were visualized with diamino-benzidine.

The expression of Versican was scored by two pathologists independently of the study. Only staining for nucleus (regardless of cytoplasmic staining) was regarded as positive. The expression was scored according to previous studies, which divided the staining intensity into none (0), mild (1), moderate (2) and intense (3) at low magnification (x200) and scored the percentage of positive tumor cells as $0 \%$ ( 0 , absent), $1-5 \%$ (1, sporadic), $6-25 \%$ (2, local), $26-50 \%$ (3, occasional), $51-75 \%$ (4, majority) and $76-100 \%$ $\left(5\right.$, large majority). ${ }^{22,31}$ The combined scores were then divided into two groups by the middle value: category 0 (score $0-3$, low expression) and category 1 (score 4-8, high expression). Human lung carcinoma tissue and normal gastric tissue are the positive and negative controls, respectively. ${ }^{31}$

\section{Plasmids}

The full-length versican sequence was amplified by $P C R$ from complementary DNA of NIH: AGS cells and then subcloned into pCDNA3.1 (+) vector (Transheep, Shanghai, China).

\section{Cell lines and culture conditions}

Cell lines involved including human GES cell line, GC cell lines AGS, HGC-27, MKN-45, MGC-803, and NCI-N87 were cultured in Dulbecco's modified Eagle's medium (Gibco, Carlsbad, CA, USA) or RMPI-1640 (Gibco) respectively, supplemented with $10 \%$ fetal bovine serum (Gibco), $50 \mathrm{U} / \mathrm{ml}$ penicillin and $50 \mu \mathrm{g} / \mathrm{ml}$ streptomycin (Gibco). All cell lines were maintained at $37^{\circ} \mathrm{C}, 5 \% \mathrm{CO}_{2}$ in a humidified atmosphere.

\section{Cell proliferation assays}

Cell proliferation was evaluated using CCK-8 (Dojindo, Kumamoto, Japan). In all, $2 \times 10^{3}$ cells per well were seeded onto 96-well plated in $100 \mu \mathrm{l}$ complete culture medium. The cells were cultured for $0,24,48,72,96 \mathrm{~h}$ before adding $10 \mu \mathrm{l} \mathrm{CCK}-8(5 \mathrm{mg} / \mathrm{ml})$ into the culture medium in each well. After a 2-h incubation at $37^{\circ} \mathrm{C}$, optical density at $450 \mathrm{~nm}$ was measured with an automatic microplate reader (Synergy4; BioTek, Winooski, VT, USA).

\section{Cell invasion assays}

The transwell chambers $(8 \mu \mathrm{m}, 24$-well format; Corning Co., New York, NY, USA) were used for cell invasion assay. A total of $4 \times 10^{4}$ cells in $100 \mu$ serum-free medium were loaded into the upper inserts, and $500 \mu \mathrm{l}$ culture medium containing $10 \%$ fetal bovine serum were loaded into the lower chamber as chemo-attractant. After a 24 -h incubation at $37^{\circ} \mathrm{C}$, the cells that had migrated through the filters were fixed with ethanol and stained with $0.1 \%$ crystal violet. Photographs were taken at $200 \times$ under microscope (BX51, Olympus, Tokyo, Japan) and the number of invaded cells was counted at $400 \times$.

\section{Statistical analysis}

All statistical analyses were performed using SPSS 20.0 software (IBM, SPSS, Chicago, IL, USA). The significance of between-group differences was estimated using Student's $t$-test, $x^{2}$ test or Wilcoxon test, as appropriate. DSS rates were calculated using the Kaplan-Meier method, with the log-rank test applied for comparison. Variables with a value of $P<0.05$ in univariate analysis were used in a subsequent multivariate analysis, based on the Cox proportional hazards model. Two-sided P-values were calculated, and a probability level of 0.05 indicated statistical significance. Statistical analyses of immunohistochemistry staining evaluation were performed using the Kruskal-Wallis one-way analysis of variance test and Mann-Whitney U-test.

\section{CONFLICT OF INTEREST}

The authors declare no conflict of interest.

\section{ACKNOWLEDGEMENTS}

This study was supported by the grant from the Science and Technology Commission of Shanghai Municipality (No.10DJ1400501), National Clinical Key Discipline (2011-2015), Priority of Shanghai key discipline of medicine (2013-2015), Shanghai R\&D public service platform construction projects (12DZ2295100), National Natural
Science Foundation of China (81472220), Shanghai Science and Technology Development Fund (Domestic Science and Technology Cooperation Project, no. 14495800300) and Ningbo Natural Science Foundation Projects (2014A610221).

\section{REFERENCES}

1 Hartgrink HH, Jansen EP, van Grieken NC, van de Velde CJ. Gastric cancer. Lancet 2009; 374: 477-490.

2 Siegel R, Ma J, Zou Z, Jemal A. Cancer statistics, 2014. CA Cancer J Clin 2014; 64: 9-29.

3 Zigrino P, Loffek S, Mauch C. Tumor-stroma interactions: their role in the control of tumor cell invasion. Biochimie 2005; 87: 321-328.

4 Ricciardelli C, Rodgers RJ. Extracellular matrix of ovarian tumors. Semin Reprod Med 2006; 24: 270-282.

5 lozzo RV. Matrix proteoglycans: from molecular design to cellular function. Annu Rev Biochem 1998; 67: 609-652

6 Dours-Zimmermann MT, Zimmermann DR. A novel glycosaminoglycan attachment domain identified in two alternative splice variants of human versican. J Biol Chem 1994; 269: 32992-32998.

7 Kusumoto T, Kodama J, Seki N, Nakamura K, Hongo A, Hiramatsu Y. Clinical significance of syndecan-1 and versican expression in human epithelial ovarian cancer. Oncol Rep 2010; 23: 917-925.

8 Ricciardelli C, Sakko AJ, Ween MP, Russell DL, Horsfall DJ. The biological role and regulation of versican levels in cancer. Cancer Metastasis Rev 2009; 28: 233-245.

9 Brown LF, Guidi AJ, Schnitt SJ, Van De Water L, Iruela-Arispe ML, Yeo TK et al. Vascular stroma formation in carcinoma in situ, invasive carcinoma, and metastatic carcinoma of the breast. Clin Cancer Res 1999; 5: 1041-1056.

10 Kischel P, Waltregny D, Dumont B, Turtoi A, Greffe Y, Kirsch S et al. Versican overexpression in human breast cancer lesions: known and new isoforms for stromal tumor targeting. Int J Cancer 2010; 126: 640-650.

11 Pirinen R, Leinonen T, Bohm J, Johansson R, Ropponen K, Kumpulainen E et al. Versican in nonsmall cell lung cancer: relation to hyaluronan, clinicopathologic factors, and prognosis. Hum Pathol 2005; 36: 44-50.

12 Touab M, Villena J, Barranco C, Arumi-Uria M, Bassols A. Versican is differentially expressed in human melanoma and may play a role in tumor development. $\mathrm{Am} J$ Pathol 2002; 160: 549-557.

13 Pukkila MJ, Kosunen AS, Virtaniemi JA, Kumpulainen EJ, Johansson RT, Kellokoski JK et al. Versican expression in pharyngeal squamous cell carcinoma: an immunohistochemical study. J Clin Pathol 2004; 57: 735-739.

14 Ghosh S, Albitar L, LeBaron R, Welch WR, Samimi G, Birrer MJ et al. Up-regulation of stromal versican expression in advanced stage serous ovarian cancer. Gynecol Oncol 2010; 119: 114-120.

15 Kodama J, Hasengaowa, Kusumoto T, Seki N, Matsuo T, Nakamura K et al. Versican expression in human cervical cancer. Eur J Cancer 2007; 43: 1460-1466.

16 Stylianou M, Skandalis SS, Papadas TA, Mastronikolis NS, Theocharis DA, Papageorgakopoulou $\mathrm{N}$ et al. Stage-related decorin and versican expression in human laryngeal cancer. Anticancer Res 2008; 28: 245-251.

17 Rahmani M, Wong BW, Ang L, Cheung CC, Carthy JM, Walinski H et al. Versican: signaling to transcriptional control pathways. Can J Physiol Pharmacol 2006; 84: 77-92.

18 Linardou H, Kalogeras KT, Kronenwett R, Kouvatseas G, Wirtz RM, Zagouri F et al. The prognostic and predictive value of mRNA expression of vascular endothelial growth factor family members in breast cancer: a study in primary tumors of high-risk early breast cancer patients participating in a randomized Hellenic Cooperative Oncology Group trial. Breast Cancer Res 2012; 14: R145.

19 Gorter A, Zijlmans HJ, van Gent H, Trimbos JB, Fleuren GJ, Jordanova ES. Versican expression is associated with tumor-infiltrating CD8-positive T cells and infiltration depth in cervical cancer. Mod Pathol 2010; 23: 1605-1615.

20 Pukkila M, Kosunen A, Ropponen K, Virtaniemi J, Kellokoski J, Kumpulainen E et al. High stromal versican expression predicts unfavourable outcome in oral squamous cell carcinoma. J Clin Pathol 2007; 60: 267-272.

21 Gulyas M, Hjerpe A. Proteoglycans and WT1 as markers for distinguishing adenocarcinoma, epithelioid mesothelioma, and benign mesothelium. J Pathol 2003; 199: 479-487.

22 Ju H, Lim B, Kim M, Noh SM, Han DS, Yu HJ et al. Genetic variants A1826H and D2937Y in GAG-beta domain of versican influence susceptibility to intestinal-type gastric cancer. J Cancer Res Clin Oncol 2010; 136: 195-201.

23 Sakko AJ, Ricciardelli C, Mayne K, Tilley WD, Lebaron RG, Horsfall DJ. Versican accumulation in human prostatic fibroblast cultures is enhanced by prostate cancer cell-derived transforming growth factor beta1. Cancer Res 2001; 61: 926-930.

24 Arslan F, Bosserhoff AK, Nickl-Jockschat T, Doerfelt A, Bogdahn U, Hau P. The role of versican isoforms $\mathrm{V} 0 / \mathrm{V} 1$ in glioma migration mediated by transforming growth factor-beta2. Br J Cancer 2007; 96: 1560-1568. 
25 Kamitani S, Yamauchi Y, Kawasaki S, Takami K, Takizawa H, Nagase $\mathrm{T}$ et al. Simultaneous stimulation with TGF-beta1 and TNF-alpha induces epithelial mesenchymal transition in bronchial epithelial cells. Int Arch Allergy Immunol 2011; 155: 119-128.

26 Mukaratirwa S, Koninkx JF, Gruys E, Nederbragt $\mathrm{H}$. Mutual paracrine effects of colorectal tumour cells and stromal cells: modulation of tumour and stromal cell differentiation and extracellular matrix component production in culture. Int J Exp Pathol 2005; 86: 219-229.

27 Willert J, Epping M, Pollack JR, Brown PO, Nusse R. A transcriptional response to Wht protein in human embryonic carcinoma cells. BMC. Dev Biol 2002; 2: 8.

28 Zhang Z, Zhang J, Miao L, Liu K, Yang S, Pan C et al. Interleukin-11 promotes the progress of gastric carcinoma via abnormally expressed versican. Int J Biol Sci 2012; 8: 383-393.

29 Wittekind C, Compton CC, Greene FL, Sobin LH. TNM residual tumor classification revisited. Cancer 2002; 94: 2511-2516.
30 Mori R, Wang Q, Danenberg KD, Pinski JK, Danenberg PV. Both beta-actin and GAPDH are useful reference genes for normalization of quantitative RT-PCR in human FFPE tissue samples of prostate cancer. Prostate 2008; 68: 1555-1560.

31 Ruiter DJ, Ferrier CM, van Muijen GN, Henzen-Logmans SC, Kennedy S, Kramer MD et al. Quality control of immunohistochemical evaluation of tumour-associated plasminogen activators and related components. European BIOMED-1 Concerted Action on Clinical Relevance of Proteases in Tumour Invasion and Metastasis. Eur J Cancer 1998; 34: 1334-1340.

(C) Oncogenesis is an open-access journal published by Nature Publishing Group. This work is licensed under a Creative Commons Attribution 4.0 International License. The images or other third party material in this article are included in the article's Creative Commons license, unless indicated otherwise in the credit line; if the material is not included under the Creative Commons license, users will need to obtain permission from the license holder to reproduce the material. To view a copy of this license, visit http://creativecommons.org/licenses/by/4.0/ 